University of Nebraska - Lincoln

DigitalCommons@University of Nebraska - Lincoln

Virology Papers

Virology, Nebraska Center for

4-12-2006

Influence of bovine respiratory syncytial virus $\mathrm{F}$ glycoprotein $N$-linked glycans on in vitro expression and on antibody responses in $\mathrm{BALB} / \mathrm{c}$ mice

\author{
Holly A. Klink \\ University of Nebraska-Lincoln \\ Ryan Brady \\ University of Nebraska-Lincoln \\ Christina L. Topliff \\ University of Nebraska-Lincoln, ctopliff2@unl.edu \\ Kent M. Eskridge \\ University of Nebraska-Lincoln, keskridge1@unl.edu \\ Subramaniam Srikumaran \\ University of Nebraska-Lincoln, ssrikumaran1@unl.edu \\ See next page for additional authors
}

Follow this and additional works at: https://digitalcommons.unl.edu/virologypub

Part of the Virology Commons

Klink, Holly A.; Brady, Ryan; Topliff, Christina L.; Eskridge, Kent M.; Srikumaran, Subramaniam; and Kelling, Clayton L., "Influence of bovine respiratory syncytial virus $\mathrm{F}$ glycoprotein $\mathrm{N}$-linked glycans on in vitro expression and on antibody responses in BALB/c mice" (2006). Virology Papers. 112.

https://digitalcommons.unl.edu/virologypub/112

This Article is brought to you for free and open access by the Virology, Nebraska Center for at DigitalCommons@University of Nebraska - Lincoln. It has been accepted for inclusion in Virology Papers by an authorized administrator of DigitalCommons@University of Nebraska - Lincoln. 


\section{Authors}

Holly A. Klink, Ryan Brady, Christina L. Topliff, Kent M. Eskridge, Subramaniam Srikumaran, and Clayton L. Kelling 
Published in Vaccine 24:16 (April 12, 2006), pp. 3388-3395; doi 10.1016/j.vaccine.2005.12.067

Copyright () 2006 Elsevier Ltd. Used by permission. http://0-www.sciencedirect.com/science/journal/0264410X

A contribution of the University of Nebraska Agricultural Research Division, Lincoln, NE 68583.

Submitted December 11, 2004; revised and accepted December 5, 2005; published online February 6, 2006.

\title{
Influence of bovine respiratory syncytial virus F glycoprotein $N$-linked glycans on in vitro expression and on antibody responses in BALB/c mice
}

\author{
Holly A. Klink, ${ }^{1}$ Ryan P. Brady, ${ }^{1}$ Christina L. Topliff, ${ }^{1}$ Kent M. Eskridge, ${ }^{2}$ \\ Subramaniam Srikumaran, ${ }^{1}$ and Clayton L. Kelling ${ }^{1}$ \\ ${ }^{1}$ Department of Veterinary and Biomedical Sciences, University of Nebraska-Lincoln, \\ East Campus Loop and Fair Street, Lincoln, NE 68583-0905, USA \\ ${ }^{2}$ Department of Statistics, University of Nebraska-Lincoln, \\ East Campus Loop and Fair Street, Lincoln, NE 68583-0905, USA \\ Corresponding author - C. L. Kelling, tel. 402 472-3040, fax 402 472-9690, email ckelling1@unl.edu
}

\begin{abstract}
Bovine respiratory syncytial virus (BRSV) is an etiological component of the bovine respiratory tract disease complex. Infection with BRSV following vaccination, or re-infection following natural infection is common since protection is incomplete. The objectives of this study were to create plasmid DNA constructs encoding single or multiple $N$-glycosylation-site deletion BRSV fusion (F) proteins, and evaluate their expression in cell culture, and potential to induce anti-BRSV F antibody responses in BALB/ c mice. Four plasmid DNAs were constructed, each encoding 1-4 N-glycosylation-site deletions: Gly4, Gly2/4, Gly1/2/4 and Gly1/2/3/4. Each of the N-glycosylation-site deletion BRSV F proteins were expressed in COS-7 cells following transfection with plasmid DNA. Inoculation of BALB/c mice with plasmid DNA, resulted in a significant anti-BRSV F IgG response to the wildtype (WT) F and glycosylation-site deletion protein Gly2/4. Gly2/4 elicited a higher antibody titer than the fully glycosylated WT F protein. Significant neutralizing antibody titers were detected following immunization with the Gly2/4 plasmid DNA. These glycosylation-site deletion BRSV F proteins will be useful to characterize the effects of glycosylation on immunogenicity in the natural host, and may lead to a new approach for the generation of BRSV vaccines.
\end{abstract}

Keywords: Bovine respiratory syncytial virus, Fusion protein, Glycosylation

\section{Introduction}

Bovine respiratory syncytial virus (BRSV) is a primary cause of lower respiratory tract disease in calves and is an etiological component of the bovine respiratory disease complex [1]. BRSV is a member of the genus Pneumovirus in the family Paramyxoviridae [2]. Infection with BRSV following vaccination, or re-infection following natural infection is common since protection is incomplete [3]. The attachment (G) and fusion (F) surface glycoproteins are the most immunogenic in humoral immunity [4]. Monoclonal antibodies to the $\mathrm{G}$ or $\mathrm{F}$ protein protect against lower respiratory tract infection [4]. Priming of mice with the $\mathrm{F}$ protein elicits protective cytotoxic T lymphocyte (CTL) and T-helper $\left(\mathrm{T}_{\mathrm{H}}\right)$ cell responses [5].

The BRSV F glycoprotein is a type I envelope glycoprotein which plays an important role in fusion of the viral envelope to the host cell membrane. The F protein causes infected cells to fuse to adjacent cells, forming syncytia, or multi-nucleated cells [6]. The F protein is synthesized as an inactive precursor, $\mathrm{F}_{0}$, which is then cleaved to form two disulfide-linked subunits, $\mathrm{F}_{1}$ and $\mathrm{F}_{2}$ [7]. The $\mathrm{F}$ protein is post-translationally modified by cleavage, folding and glycosylation before being transported to the cell surface [8]. Depending on the BRSV strain, the F protein may have either three or four $N$-glycosylation sites. Two 
or three sites are located on the $\mathrm{F}_{2}$ subunit, while one site is located on the $F_{1}$ subunit $[9,10]$. Glycosylation is an important modification that can affect the folding, transport, and immunogenicity of proteins [11].

Carbohydrate moieties on surface glycoproteins, such as the $\mathrm{F}$ protein, may modulate immunogenicity of the protein. Glycans can shield large regions of the protein surface, providing protection from proteases and masking epitopes. It is also possible that the removal of carbohydrates cause a shift in the conformation of the polypeptide backbone, altering the recognition of immunogenic epitopes [12]. Palomo et al. [13], showed that removal of carbohydrates on the $G$ protein of human respiratory syncytial virus (HRSV) reduced recognition by monoclonal antibodies (MAbs). Of the 18 MAbs that originally recognized the fully $\mathrm{O}$ - and $\mathrm{N}$-glycosylated protein, only five MAbs recognized the unglycosylated $G$ protein. In this case, the carbohydrates comprised the epitope, or were necessary for recognition of the epitope by the MAbs [13].

Completely effective vaccines for both HRSV and BRSV are yet to be developed. Previously, a formalin-inactivated (FI) HRSV vaccine was used which exacerbated illness in vaccinated children following natural exposure to the virus [14]. Vaccine-enhanced respiratory disease has also been reported in calves using an experimental FIBRSV vaccine [15]. A number of approaches have been explored to develop a more effective vaccine. One approach has been the development of DNA vaccines, which have advantages over the live- or FI-vaccines. DNA vaccines are safer, more cost-effective and can be manipulated to alter the qualitative and quantitative humoral and cellular immune responses [16].

Plasmid DNA vaccines encoding the $G$ and $F$ proteins of HRSV have been effective in inducing neutralizing antibodies. Intramuscular inoculation with plasmid DNA encoding the F glycoprotein resulted in high neutralizing antibody titers, protection against live challenge and production of interferon- $\gamma$ and CD8+ CTLs [17]. The immunization of mice with plasmid DNA encoding the fulllength and secreted HRSV G resulted in a balanced Th1/ Th2 response following virus challenge [17]. The objectives of this study were to create plasmid DNA constructs encoding WT and $\mathrm{N}$-linked glycosylation-site deletion BRSV $F$ proteins and to characterize expression in cell culture and induction of antibody responses in BALB/c mice.

\section{Materials and methods}

\subsection{Cells and viruses}

Bovine turbinate (BT) cells (National Veterinary Services Laboratory, Ames, IA) and African green monkey kidney (COS-7) cells (American Type Culture Collection, CRL-1651, Rockville, MD) were grown in Dulbecco's Modified Eagle Medium (DMEM) supplemented with $10 \%$ equine serum (Hyclone, Logan, UT) and maintained in a $37^{\circ} \mathrm{C}$ humidified chamber with $5 \% \mathrm{CO}_{2}$. Confluent monolayers were infected with BRSV strain 375 at a multiplicity of infection (m.o.i.) of 0.01 in tissue culture flasks. Inoculated cell cultures were maintained at $33^{\circ} \mathrm{C}$ in a humidified chamber with $5 \% \mathrm{CO}_{2}(\sim 2$ weeks $)$ until the cells developed $50 \%$ cytopathic effect (CPE). Cells were frozen at $-80^{\circ} \mathrm{C}$, thawed, dispensed into aliquots, then frozen again at $-80^{\circ} \mathrm{C}$ until used. Recombinant vaccinia virus expressing T7 polymerase (vvT7) was kindly provided by Dr. Bernard Moss (National Institute of Health, Bethesda, $\mathrm{MD})$.

\subsection{Construction of plasmid DNA vector encoding the wild- type BRSV F glycoprotein}

Viral RNA was isolated from BRSV-infected BT cells using TRIZOL LS reagent (Invitrogen, Carlsbad, CA) according to the manufacturer's instructions. The $1800 \mathrm{bp}$ BRSV F glycoprotein cDNA sequence was generated from total RNA using Superscript II reverse transcriptase (Invitrogen) and the primer F2, 5'-GGATCCAAAAATGCAGGTCTTGGCGGATAC-3', complementary to nucleotide base numbers 1801-1824 of the BRSV 375 F glycoprotein, with a BamHI restriction site incorporated (underlined). The BRSV F cDNA was amplified using Taq polymerase (Invitrogen), with primers F2 and F1, 5'-GGATCCATAAGGATGGCGGCAACAGC-3', corresponding to nucleotide base numbers 1-14 of BRSV F. The BRSV F specific primers were purchased from Sigma Genosys (Woodlands, TX). The reaction mixture was denatured at $94^{\circ} \mathrm{C}$ for $1 \mathrm{~min}$, annealed at $50^{\circ} \mathrm{C}$ for $1 \mathrm{~min}$ and extended at $72^{\circ} \mathrm{C}$ for $2 \mathrm{~min}$ for a total of 30 cycles, followed by an additional extension of $7 \mathrm{~min}$ at $72{ }^{\circ} \mathrm{C}$.

The BRSV F PCR product was gel purified (QIAEX II Gel Extraction Kit, QIAGEN, Valencia, CA) and subcloned into the pCR 2.1 vector using the TA Cloning Kit (Invitrogen). The BRSV F cDNA was excised from the pCR 2.1 vector using restriction enzymes SpeI and NotI, and ligated using T4 DNA ligase into the mammalian expression vector, pcDNA 3.1/His (Invitrogen), previously digested with NotI and XbaI, creating the construct 3.1/ His/F. This placed the BRSV F cDNA downstream of the T7 RNA polymerase and upstream of the bovine growth hormone polyadenylation signal sequence. DNA sequencing (DNA Sequencing Facility, Iowa State University, Ames, IA) was performed after cloning to confirm the insert was in the proper reading frame.

\subsection{Construction of N-glycosylation-site deletion BRSV F proteins}

The $\mathrm{N}$-glycosylation deletion BRSV F protein coding regions were generated by replacing the asparagine triplet (AAC) at positions N27, N70, N120 and N500 of the 3.1/His/F cDNA with the alanine triplet (GCC) using the QuikChange Site-Directed Mutagenesis Kit (Stratagene, La Jolla, CA) according to the manufacturer's instructions. Site-directed mutagenesis was performed using Pfu- 


\begin{tabular}{|c|c|c|}
\hline $\begin{array}{l}\mathrm{N} \text {-glycan } \\
\text { Location }\end{array}$ & Primer & Composition \\
\hline \multirow[t]{2}{*}{ N27 } & Gly 1a & $\begin{array}{l}\text { 5'-CTACCTAATGTGACACATATCACTTTATGCCAA- } \\
\text { GCCATAACAGAAG-3' }\end{array}$ \\
\hline & Gly $1 b$ & $\begin{array}{l}\text { 5'-CTTCTGTTATGGCTTGGCATAAAGTGATATGTGT- } \\
\text { CACATAGGTAG-3' }\end{array}$ \\
\hline \multirow[t]{2}{*}{ N70 } & Gly2a & $\begin{array}{l}\text { 5'-GGTAACAATAGAGTTGAGCAAAATACAAAAAA- } \\
\text { ATGTGTGTGCCAGTACTG-3' }\end{array}$ \\
\hline & Gly $2 b$ & $\begin{array}{l}\text { 5'-CAGTACTGGCACACACATTTTTTTGTATTTTGCT- } \\
\text { CAACTCTATTGTTACC-3' }\end{array}$ \\
\hline \multirow[t]{2}{*}{ N120 } & Gly3a & $\begin{array}{l}\text { 5'-GAGTTGATACATTATCCAAGAGCCTCTACAAAA- } \\
\text { ACCTTTTATGGGC-3' }\end{array}$ \\
\hline & Gly3b & $\begin{array}{l}\text { 5'-GCCCATAAAACCTTTTTGTAGAGGCTCTTGGAT- } \\
\text { AATGTATCAACTC-3' }\end{array}$ \\
\hline \multirow[t]{2}{*}{ N500 } & Gly4a & $\begin{array}{l}\text { 5'-GCCCAAGTAAATGCAAAAATAGCCCAAAGCTTG- } \\
\text { GCTTTCATACG-3' }\end{array}$ \\
\hline & Gly $4 b$ & $\begin{array}{l}\text { 5'-CGTATGAAAGCCAAGCTTTGGGCTATTTTTGCA- } \\
\text { TTTACTTGGGC-3' }\end{array}$ \\
\hline
\end{tabular}

Figure 1. Glycosylation-site specific primers used to make BRSV F N-glycosylation-site deletion proteins for DNA inoculation of BALB/c mice. The double nucleotide change is underlined. The first two nucleotides of the triplet codons were changed to exchange the asparagine triplet codon (AAC) with an alanine triplet codon (GCC) to create plasmid DNA encoding N-glycosylationsite deletion proteins: Gly4, Gly2/4, Gly1/2/4 and Gly1/2/3/4.

Turbo $^{\mathrm{TM}}$ DNA polymerase, and glycosylation-site specific primers (Figure 1). BRSV F N-glycosylation-site specific primers containing the two nucleotide changes were purchased from Sigma Genosys (Woodlands, TX). The reaction mixture was denatured at $95^{\circ} \mathrm{C}$ for $30 \mathrm{~s}$, annealed at $55^{\circ} \mathrm{C}$ for $1 \mathrm{~min}$ and extended at $68^{\circ} \mathrm{C}$ for $14 \mathrm{~min}$, for a total of 16 cycles. Following temperature cycling, the product was treated with $\mathrm{DpnI}$ endonuclease at $37^{\circ} \mathrm{C}$ for $1 \mathrm{~h}$ to digest the parental DNA. The PCR-synthesized plasmid DNA was then transformed into XL-1 Blue Supercompetent Cells (Stratagene). Ampicillin-resistant colonies were selected and plasmid DNA extracted using the Wizard Plus Mini-Prep Kit (Promega) according to the manufacturer's instructions. The nucleotide exchanges were confirmed by DNA sequencing. Plasmid DNA encoding the glycosylation-site deletion proteins was identified according to the deleted glycosylation-site(s) (i.e. Gly2/4 had the second and fourth $N$-glycosylation-sites deleted).

\subsection{Expression of BRSV F N-glycosylation-site deletion pro- teins in mammalian cells}

Expression of the WT and N-glycosylation-site deletion BRSV F proteins was evaluated in COS-7 cells following transfection using a vaccinia virus-T7 RNA polymerase expression system [18]. Following infection with T7-vaccinia virus, COS-7 cells were transfected with plasmid DNA using a cationic lipid-mediated method (LipofectAMINE 2000 Reagent, Invitrogen) according to the manufacturer's instructions.
Twenty-four hours following transfection, the COS7 cells were fixed with $20 \%$ acetone (v/v) in phosphatebuffered saline (PBS). The BRSV F protein was detected using an immunoperoxidase staining protocol [19] with MAb 8G12, specific for BRSV F, as the primary antibody and biotinylated horse anti-mouse $\operatorname{IgG}(\mathrm{H}+\mathrm{L})$ (Vector Laboratories, Burlingame, CA) as the secondary antibody. Antibody binding was detected using streptavidin horseradish peroxidase conjugate (Zymed, San Francisco, CA) and 3-amino-9-ethyl-carbazole substrate (AEC, Sigma, St. Louis, MO). Additionally, cells were transfected and lysed with $0.5 \%$ NP-40 lysis buffer, then proteins separated by discontinuous SDS-PAGE electrophoresis. The separated proteins were transferred onto a nitrocellulose membrane and non-specific sites blocked by incubation with PBS, $\mathrm{pH}$ 7.6, containing 5\% nonfat dry milk. The membrane was then incubated with the primary antibody, MAb 8G12 (1:1000), followed by alkaline phosphatase-labeled goat anti-mouse IgG (H + L) (KPL, Gaithersburg, MD) as the secondary antibody. Antibody binding was detected using 5-bromo-4-chloro-3-indolylphosphate/nitroblue tetrazolium substrate (KPL, Gaithersburg, MD).

\subsection{DNA inoculation of $B A L B / c$ mice}

Prior to initiation of the experiments, this project was reviewed and approved by the University of Nebraska Institutional Animal Care and Use Committee to ensure humane use and treatment of animals, and guidelines were adhered to throughout the course of the study. Plasmid 
DNA encoding the WT F and the $N$-glycosylation-site deletion proteins was purified using a plasmid Mega kit from QIAGEN according to the manufacturer's instructions. The purified DNA pellet was resuspended in $0.89 \%$ $\mathrm{NaCl}$. Seven-week-old female, specific pathogen-free BALB/c mice, purchased from Charles River Laboratories (Wilmington, MA), were housed in BL-2 rooms at the Animal Research Facility, University of Nebraska-Lincoln.

The mice were assigned to one of seven treatment groups: (1) pcDNA 3.1/His encoding the fully glycosylated BRSV F protein (WT F), (2) pcDNA 3.1/His encoding a single glycosylation-site deletion protein (Gly4), (3) pcDNA 3.1/His encoding a double glycosylation-site deletion protein (Gly2/4), (4) pcDNA 3.1/His encoding a triple glycosylation-site deletion protein $(\mathrm{Gly} 1 / 2 / 4)$, (5) pcDNA 3.1/His encoding a quadruple glycosylation-site deletion protein $(\mathrm{Gly} 1 / 2 / 3 / 4)$, (6) live BRSV virus, or (7) no treatment. Each treatment group was comprised of four or five mice. Mice were inoculated in the rectus femoris muscle with $100 \mu \mathrm{g}$ of plasmid DNA. Booster inoculations were given at 4 and 8 weeks, by the same route and with the same dose of plasmid DNA. Three weeks following the final inoculation (day 78), all mice were anesthetized by injecting intramuscularly (IM) with $40 \mu \mathrm{g} / \mathrm{g}$ ketamine and $6 \mu \mathrm{g} / \mathrm{g}$ Xylazine and bled by cardiac puncture. An equal amount of Alsever's solution was added to the blood. The mice were then euthanatized by $\mathrm{CO}_{2}$ inhalation.

\subsection{Antibody responses in mice following plasmid DNA inoculation}

Plasma was analyzed for anti-BRSV F antibodies using an indirect enzyme-linked immunosorbent assay (ELISA), with modifications [20]. BT cells infected with BRSV using an m.o.i. of 0.1 were used as antigen and propagated in 96-well microtiter plates. Following incubation for 4 days, cells were fixed with $20 \%$ acetone in PBS (v/v). Infected cells were blocked with $1 \%$ bovine serum albumin (BSA) in PBS with $0.15 \%$ Tween for $1 \mathrm{~h}$ at $37^{\circ} \mathrm{C}$. Two-fold dilutions (1:10-1:1280) of mouse plasma were prepared, added to the cells and incubated for $1 \mathrm{~h}$ at $37^{\circ} \mathrm{C}$. Cells were then incubated with alkaline phosphatase-labeled goat anti-mouse IgG $(\mathrm{H}+\mathrm{L})$ (KPL, Gaithersburg, $\mathrm{MD})$, diluted 1:1000 in $0.1 \%$ BSA in PBS-Tween, for $1 \mathrm{~h}$ at $37^{\circ} \mathrm{C}$. The substrate, $p$-nitrophenyl phosphate, was then added, incubated at room temperature for $30 \mathrm{~min}$ and the optical density (OD) values were determined using a microplate reader (MR 700, Dynatech Laboratories) at $410 \mathrm{~nm}$.

Neutralizing antibody titers were determined by combining serial two-fold dilutions (1:2-1:256) of heat-inactivated $\left(56^{\circ} \mathrm{C}\right.$ for $\left.30 \mathrm{~min}\right)$ plasma with BRSV $\left(150 \mathrm{TCID}_{50} /\right.$ $50 \mu \mathrm{l}$ ) in 96-well microtiter plates for $1 \mathrm{~h}$ at $37^{\circ} \mathrm{C}$ with $5 \%$ $\mathrm{CO}_{2}$. Following incubation, $1 \times 10^{5} \mathrm{BT}$ cells were added to each well and incubated 5 days at $37^{\circ} \mathrm{C}$. Cells were examined microscopically for viral CPE and then fixed with $20 \%$ acetone in PBS (v/v). Plates were stained with an immunoperoxidase staining assay [19] and virus neutraliz- ing antibody titers were determined as the highest plasma dilution inhibiting BRSV CPE.

\subsection{Statistical analysis}

Results in the different treatment groups of mice for both the ELISA and neutralization assays were compared and analyzed statistically using analysis of variance [21]. ELISA antibody and virus neutralizing antibody titers for each treatment group were compared to all other treatment groups to identify difference between treatments. $P$ values of $<0.05$ were considered to be statistically significant.

\section{Results}

\subsection{Plasmid DNA vectors encoding BRSV F N-glycosylation- site deletion proteins}

The plasmids encoding the WT and each of the four BRSV F N-glycosylation deletion proteins for DNA inoculation were constructed and DNA sequencing confirmed that the specific asparagine triplet(s) were replaced with alanine triplet(s) for each of the glycosylation-site deletion plasmids, as well as in the proper reading frame. The vectors encoded: (1) WT BRSV F protein; (2) BRSV F Gly4 protein (deletion of N500); (3) BRSV F Gly2/4 protein (deletion of N70 and N500); (4) BRSV F Gly1/2/4 protein (deletion of N27, N70 and N500) or (5) BRSV F Gly1/2/3/4 protein (deletion of N27, N70, N120 and N500) (Figure 2). Using a T7-vaccinia virus expression system, transcription was under control of the T7 promoter.

\subsection{COS-7 cells express the BRSV F N-glycosylation-site deletion proteins}

Expression of the F proteins was evaluated using an immunoperoxidase assay. Cytoplasmic staining was detected in the COS-7 cells transfected with each of the plasmid

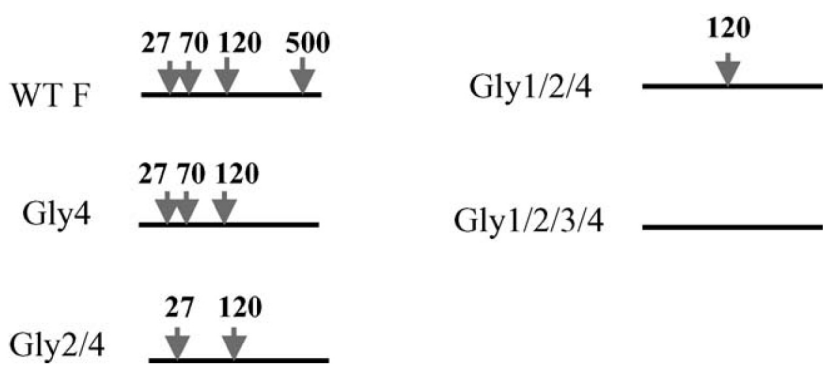

Figure 2. Schematic drawing of the plasmid DNAs encoding the wild-type (WT) and $N$-glycosylation-site deletion BRSV F proteins Gly4, Gly2/4, Gly1/2/4, and Gly1/2/3/4 constructed using site-directed mutagenesis. Arrows illustrate the location of the N-glycans. The fully glycosylated WT F has N-glycans located at asparagine residues 27, 70, 120 and 500. Each plasmid DNA encoding a different glycosylation-site deletion protein was named according to the specific $N$-glycan site(s) deleted. 

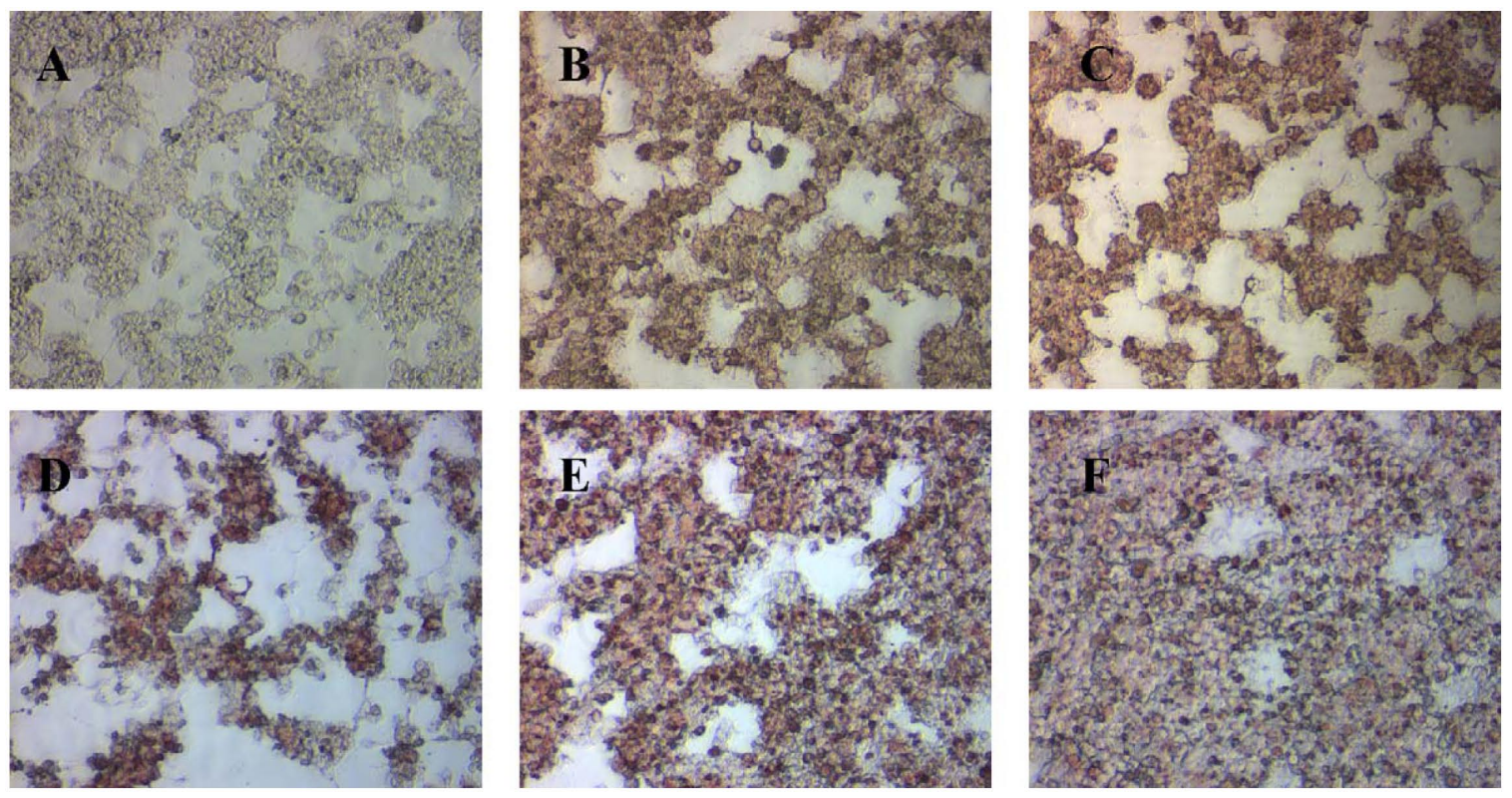

Figure 3. Cytoplasmic staining using an immunoperoxidase assay in COS-7 cells transiently transfected with plasmid DNA encoding the WT and N-glycosylation-site deletion BRSV F proteins. (A) COS-7 cells transfected with the pcDNA 3.1 backbone, (B) COS7 cells transfected with DNA encoding the WT F protein. COS-7 cells transfected with DNA encoding the glycosylation-site deletion mutants, (C) Gly4, (D) Gly2/4, (E) Gly1/2/4 and (F) Gly1/2/3/4 mutant. Expression of the F protein was detected using MAb 8 G12.

DNAs encoding the $\mathrm{N}$-glycosylation-site deletion BRSV F proteins (Figure 3). The staining intensity of cells transfected with each plasmid DNA construct was comparable to staining of cells transfected with the WT F. No staining was observed in the negative control, COS-7 cells transfected with the plasmid pcDNA 3.1 backbone.

Cell lysates were collected from COS-7 cells transfected with plasmid DNA encoding the BRSV F WT and $\mathrm{N}$-glycosylation-site deletion proteins. Western blot analyses showed that each $\mathrm{N}$-glycosylation-site deletion protein and the WT F protein resolved as a $68 \mathrm{kDa}$ band, with the $\mathrm{F}_{1}$ subunit resolving as a faint $48 \mathrm{kDa}$ band (data not shown).

\subsection{BRSV F antibody response of BALB/c mice following plas- mid DNA inoculation}

To evaluate the IgG antibody response, plasma samples from mice immunized with plasmid DNA encoding the BRSV F N-glycosylation-site deletion proteins were analyzed using an indirect ELISA using BRSV-infected BT cells as antigen. Antibody titers were determined by the endpoint at which the $\mathrm{OD}_{410 \mathrm{~nm}}$ given by the post-inoculation plasma was higher than the pre-inoculation $\mathrm{OD}_{410 \mathrm{~nm}}$ at the corresponding dilution, plus two times the standard deviation given by the pre-inoculation plasma. Also, the $\mathrm{OD}_{410 \mathrm{~nm}}$ values given by post-inoculation plasma were divided by the $\mathrm{OD}_{410 \mathrm{~nm}}$ values given by pre-inoculation plasma at the corresponding dilution to determine the signal to noise (S:N) ratio (Figure 4). Plasma collected from the pre-inoculation bleed and from weeks 2 and 6 did not have a detectable antibody response (data not shown). Plasma collected on day 78 from mice inoculated with the plasmid DNA encoding the BRSV F N-glycosylation-site deletion proteins had mean ELISA antibody titers that ranged from $<1: 10$ to 1:56 (Table 1). Plasma from mice immunized IM with live BRSV was used as a positive control for the ELISA. Plasma collected from these mice had a mean BRSV F-specific antibody titer of 1:80. Inoculation with plasmid DNA encoding the WT F and Gly2/4 resulted in development of significant $(P<0.05)$ BRSV antibody titers. Mice in the WT F and Gly2/4 groups had mean antibody titers of $1: 34$ and 1:56, respectively. The mice inoculated with Gly4, Gly1/2/4, Gly1/2/3/4 and the negative control group (no treatment) did not develop a significant antibody response.

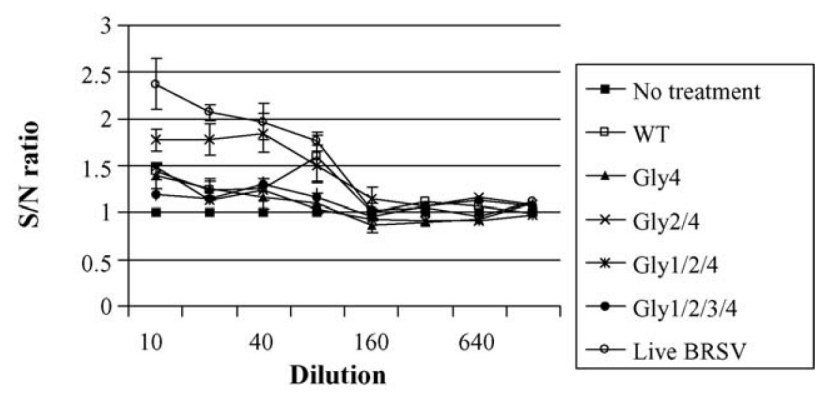

Figure 4. Anti-BRSV F IgG antibody response in BALB/c mice following inoculation with WT F, Gly4, Gly2/4, Gly1/2/4, Gly1/2/3/4, live BRSV, or no treatment. An indirect ELISA was used to evaluate the antibody responses to the plasmid DNA encoding the BRSV F proteins. Signal to noise (S:N) ratios were calculated by dividing the $\mathrm{OD}_{410 \mathrm{~nm}}$ given by the post-inoculation plasma by the $\mathrm{OD}_{410 \mathrm{~nm}}$ given by the pre-inoculation plasma at the corresponding dilution. 
Table 1. Anti-BRSV IgG antibody responses in BALB/c mice following inoculation with WT F, glycosylation-site deletion constructs: Gly4, Gly2/4, Gly1/2/4 and Gly1/2/3/4; live BRSV; or no treatment

\begin{tabular}{lll}
\hline Group & ELISA antibody titers & Neutralizing antibody titers $^{\mathrm{b}}$ \\
\hline Live BRSV & $1: 80^{\mathrm{A}}$ & $1: 128^{\mathrm{A}}$ \\
WT F & $1: 34^{\mathrm{A}, \mathrm{B}}$ & $1: 25^{\mathrm{B}, \mathrm{C}}$ \\
Gly4 & $1: 20^{\mathrm{B}, \mathrm{C}}$ & $1: 20^{\mathrm{B}, \mathrm{C}}$ \\
Gly2/4 & $1: 56^{\mathrm{A}}$ & $1: 34^{\mathrm{B}}$ \\
Gly1/2/4 & $1: 10^{\mathrm{B}, \mathrm{C}}$ & $<1: 10^{\mathrm{C}}$ \\
Gly1/2/3/4 & $<1: 10^{\mathrm{C}}$ & $<1: 10^{\mathrm{C}}$ \\
Negative & $<1: 10^{\mathrm{C}}$ & $<1: 10^{\mathrm{C}}$ \\
\hline
\end{tabular}

${ }^{a}$ The mean endpoint antibody titers were determined by the last dilution in which the post-inoculation $\mathrm{OD}_{410}$ was higher than the preinoculation $\mathrm{OD}_{410}$ plus two-times the standard deviation. Titers that have no common letters are significantly different $(P<0.05)$.

${ }^{b}$ Mean neutralizing antibody titers were determined at $100 \%$ viral inhibition by immunoperoxidase staining. Titers that have no common letters are significantly different $(P<0.05)$.

Plasma was also analyzed for virus neutralizing antibodies against BRSV. Plasma collected on day 78 from mice inoculated with the plasmid DNA encoding the $\mathrm{N}$ glycosylation-site deletion proteins had mean neutralizing antibody titers that ranged from $<1: 10$ to 1:34 (Table 1). Of the four plasmid DNA constructs encoding $N$-glycosylation-site deletion(s) tested, only the Gly2/4 glycosylation-site deletion construct elicited development of significant $(P<0.05)$ BRSV neutralizing antibodies in mice. Mice inoculated with WT F, Gly4, Gly1/2/4 and Gly1/2/3/4 plasmid DNA, along with the negative control group did not develop significant $(P<0.05)$ BRSV neutralizing antibody responses. The positive control group, mice inoculated with live virus, developed a relatively high mean virus neutralizing titer of 1:128 (Table 1).

\section{Discussion}

To characterize the effects of the four $\mathrm{N}$-glycans of BRSV F protein on expression in cell culture and immunogenicity in BALB/c mice, four plasmid DNAs were constructed, each encoding a protein with 1-4 N-glycosylation-site(s) deleted: Gly4, Gly2/4, Gly1/2/4 and Gly $1 / 2 / 3 / 4$. The deletion mutants were constructed by replacing the corresponding $\mathrm{N}$-glycosylation-site(s) of each plasmid DNA with an alanine codon, preventing $\mathrm{N}$ linked glycosylation at that site. The plasmid DNAs encoding the BRSV WT F and N-glycosylation-site deletion proteins were transfected into COS-7 cells to evaluate protein expression and were inoculated into BALB/c mice to evaluate their potential to induce antibody responses. To our knowledge, this is the first report of a study comparing the effects of multiple $\mathrm{N}$-glycosylation-site deletions of the BRSV F protein on antibody response using plasmid DNA.

Analyses of expression of the $\mathrm{N}$-glycosylation-site deletion proteins in transfected COS-7 cells by an immuno- peroxidase assay demonstrated that the protein expression among these constructs was comparable and similar to that of the wild-type protein. Additionally, expression of the plasmid DNA encoding BRSV F WT or N-glycosylation-site deletion proteins in COS-7 cells was evaluated by Western blot analyses. The $\mathrm{F}$ protein resolved as a $68 \mathrm{kDa}$ band and the $\mathrm{F}_{1}$ subunit resolved as a faint $48 \mathrm{kDa}$ band in each cell lysate.

Antibody responses of mice inoculated with the plasmid DNA encoding the WT F or N-glycosylation-site deletion proteins were analyzed using an indirect ELISA and virus neutralizing antibody assay. Among the BRSV N-glycosylation-site deletion protein groups, mice inoculated with Gly2/4 developed the highest ELISA titer and were the only group that developed a significant neutralizing titer. The Gly2/4 ELISA titers were greater than those elicited by the WT F protein. The increase in antibody response in the Gly2/4 group may be attributed to the unmasking of an epitope or to a conformational change in the protein exposing an epitope when both the second and fourth N-glycans are deleted, since the single deletion, Gly4, did not induce a significant antibody titer with either assay.

Removal of BRSV F N-glycans resulted in decreased anti-BRSV F-specific antibody responses when BALB/ c mice were inoculated with three of the four $\mathrm{N}$-glycosylation-site deletion constructs. Mice inoculated with the single (Gly4), the triple (Gly1/2/4), and the quadruple (Gly1/2/3/4) N-glycosylation-site deletion constructs did not develop significant ELISA or virus neutralizing antibody titers compared to the negative control mice. The selective deletion of certain glycans may result in a change in the protein conformation, thereby changing epitope presentation. Complete removal of $\mathrm{N}$-glycans may also have inhibited the folding and transport of the protein to the cell surface, preventing exposure of the protein to antigen presenting cells. This could explain why mice inoculated with Gly1/2/3/4 did not develop measurable antibody responses detectable by ELISA or neutralizing antibody assays.

Similar observations were made with the G glycoprotein of HRSV [13]. The complete removal of the $O$ - and $\mathrm{N}$-glycans resulted in only five of $18 \mathrm{MAbs}$ recognizing HRSV G protein, compared to the completely glycosylated protein, which was recognized by all 18 MAbs. These findings showed that the $\mathrm{O}$ - and $\mathrm{N}$-glycans were crucial for antigenicity of the HRSV G glycoprotein [13].

Taken together, the results of this study demonstrate that the expression and antibody recognition of BRSV F protein epitopes are influenced by $N$-glycosylation. The removal of three or four $\mathrm{N}$-glycosylation-sites from the BRSV F protein, Gly $1 / 2 / 4$ and Gly1/2/3/4, altered the protein such that antibody recognition was abolished. The absence of antibody response may be a result of a protein conformational change affecting epitope recognition or alteration in the transport of the protein to the cell surface. Certain glycans may also mask epitopes. The greater mean ELISA antibody and virus neutralizing titers of 
Gly2/4 than those elicited by the WT F protein suggest unmasking of an epitope. Similar results were observed with the gp70 protein of Rauscher murine leukemia virus, where removal of carbohydrates from the protein improved reactivity to most MAbs [22]. Similarly, the introduction of a glycosylation-site at residue 63 of the 1969 influenza virus caused the virus to be unreactive with the antibody specific for that residue, confirming that the addition of a glycosylation-site can mask epitopes and alter reactivity of antibodies with a viral protein [23].

Bovine CD4+ $\mathrm{T}$ cell epitopes are distributed within the $\mathrm{F}_{1}$ subunit (peptides 99 and 100) of the BRSV F protein [24]. Several of these regions, which were recognized by the CD4+ $\mathrm{T}$ cells from calves, are adjacent to previously identified B cell epitopes [25]. The antigenic sites for neutralizing MAbs to the HRSV F protein have also been mapped, primarily to the $\mathrm{F}_{1}$ subunit [26-28]. One region is near the $\mathrm{C}$ terminal-end of the cysteine-rich region and not far from the heptad repeat [27]. Other highly conserved neutralizing epitopes have been mapped to the amino-terminal third of the $\mathrm{F}_{1}$ subunit, near the proteolytic activation site [28]. The location of the individual glycosylation-site on the $\mathrm{F}_{1}$ subunit could inhibit recognition of one or more antigenic sites. Also, the multiple glycans located on the $\mathrm{F}_{2}$ subunit may account for so few epitopes being mapped to this area.

In summary, glycosylation affects how the BRSV F protein elicits a humoral immune response. The Gly2/4 deletion protein elicited the greatest mean ELISA antibody titer of the glycosylation-site deletion proteins tested, which was greater than the mean titer elicited by the fully glycosylated WT F. It was also the only glycosylation-site deletion protein that elicited a significant virus neutralizing antibody titer. Gly4, Gly1/2/4 and Gly1/2/3/4 did not elicit a significant ELISA or virus neutralizing antibody response. Continued studies using BRSV F glycosylation-site deletion proteins in the natural host to characterize the effects of glycosylation on immunogenicity may lead to a new approach for generation of BRSV vaccines [29].

\section{References}

1. D. G. Bryson, M. S. McNulty, E. F. Logan, and P. F. Cush, Respiratory syncytial pneumonia in young calves: clinical and pathologic findings, Am J Vet Res 44 (1983), pp. 1648-1688.

2. R. I. B. Francki, C. M. Fauquet, D. L. Knudson, and F. Brown, Classification and nomenclature of viruses, Fifth Report of the International Committee on Taxonomy of Viruses, SpringerVerlag, New York and Wien (1991).

3. J. C. Baker, J. A. Ellis, and E. G. Clark, Bovine respiratory syncytial virus, Vet Clin North Am Food Anim Pract 13 (1997), pp. 425-454.

4. E. E. Walsh, J. J. Schlesinger, and M. W. Brandriss, Protection from respiratory syncytial virus infection in cotton rats by passive transfer of monoclonal antibodies, Inf Immunol 43 (1984), pp. 756-758.
5. G. Taylor, L. H. Thomas, S. G. Wyld, J. Furze, P. Sopp, and C. J. Howard, Role of T-lymphocyte subsets in recovery from respiratory syncytial virus infection in calves, J Virol 69 (1995), pp. 6658-6664.

6. E. E. Walsh and J. Hruska, Monoclonal antibodies to respiratory syncytial virus protein: identification of the fusion protein, J Virol 47 (1989), pp. 171-177.

7. A. Sheid and P. W. Choppin, Two disulfide-linked polypeptide chains constitute the active $\mathrm{F}$ of paramyxoviruses, $\mathrm{Vi}$ rol 80 (1977), pp. 54-66.

8. P. L. Collins and G. Mottet, Post-translational processing and oligomerization of the fusion glycoprotein of human respiratory syncytial virus, J Gen Virol 72 (1991), pp. 3095-3101.

9. R. A. Lerch, K. Anderson, V. L. Amann, and G. W. Wertz, Nucleotide sequence of the bovine respiratory syncytial virus fusion protein of mRNA and expression from a recombinant vaccinia virus, Virol 181 (1991), pp. 118-131.

10. M. K. Pastey and S. K. Samal, Structure and sequence comparison of bovine respiratory syncytial virus fusion protein, Virus Res 29 (1993), pp. 195-202.

11. R. W. Doms, R. A. Lamb, J. K. Rose, and A. Helenius, Folding and assembly of viral membrane proteins, Virol 193 (1993), pp. 545-562.

12. P. M. Rudd, T. Elliott, P. Cresswell, I. A. Wilson, and R. A. Dwek, Glycosylation and the immune system, Science 291 (2001), pp. 2370-2376.

13. C. Palomo, B. Garcia-Barreno, C. Penas, and J. A. Melero, The $\mathrm{G}$ protein of human respiratory syncytial virus: significance of carbohydrate side-chains and the C-terminal end to its antigenicity, J Gen Virol 72 (1991), pp. 669-675.

14. A. Z. Kapikain, R. H. Mitchell, R. M. Chanock, R. A. Shvedoff, and C. E. Stewart, An epidemiological study on altered clinical reactivity to respiratory syncytial (RS) virus infection in children previously vaccinated with an inactivated RS virus vaccine, Am J Epidemiol 89 (1969), pp. 405-421.

15. L. J. Gershwin, E. S. Schelegle, R. A. Gunther, M. L. Anderson, A. R. Woolums, and D. R. Larochelle et al., A bovine model of vaccine enhanced respiratory syncytial virus pathophysiology, Vaccine 16 (1998), pp. 1225-1236.

16. S. Gurunathan, D. M. Klinman, and R. A. Seder, DNA vaccines: immunology, application, and optimization, Annu Rev Immunol 18 (2000), pp. 927-974.

17. X. Li, S. Sambhara, C. X. Li, M. Ewasyshyn, M. Parrington, and J. Caterini et al., Protection against respiratory syncytial virus infection by DNA immunization, J Exp Med 188 (1998), pp. 681-688.

18. T. R. Fuerst, E. G. Niles, F. W. Studier, and B. Moss, Eukaryotic transient-expression system based on recombinant vaccinia virus that synthesizes bacteriophage T7 RNA polymerase, Proc Natl Acad Sci USA 83 (1986), pp. 8122-8126.

19. B. W. Brodersen and C. L. Kelling, Effect of concurrent experimentally induced bovine respiratory syncytial virus and bovine viral diarrhea virus infection on respiratory tract and enteric diseases in calves, Am J Vet Res 59 (1998), pp. 1423-1430. 
20. R. A. Tripp, D. Moore, L. Jones, W. Sullender, J. Winter, and L. J. Anderson, Respiratory syncytial virus G and/or $\mathrm{SH}$ protein alters Th1 cytokines, natural killer cells, and neutrophils responding to pulmonary infection in BALB/ c mice, J Virol 73 (1999), pp. 7099-7107.

21. Statistical Analysis System (SAS) Users Guide, Version 6, SAS Institute Inc., Cary, NC (1996).

22. S. Alexander and J. H. Elder, Carbohydrate dramatically influences immune reactivity of antisera to viral glycoprotein antigens, Science 226 (1984), pp. 1328-1330.

23. J. J. Skehel, D. J. Stevens, R. S. Daniels, A. R. Douglas, M. Knossow, and I. A. Wilson et al., A carbohydrate side chain on hemagglutinins of Hong Kong influenza viruses inhibit recognition by a monoclonal antibody, Proc Natl Acad Sci USA 81 (1984), pp. 1779-1783.

24. M. H. Fogg, K.R. Parsons, L. H. Thomas, and G. Taylor, Identification of CD4+ T cell epitopes on the fusion (F) and attachment $(\mathrm{G})$ proteins of bovine respiratory syncytial virus (BRSV), Vaccine 19 (2001), pp. 3226-3240.

25. J. P. Langedijk, R. H. Meloen, and J. T. van Oirschott, Identification of a conserved neutralizing site in the first heptad repeat of the fusion protein of respiratory syncytial virus, Arch Virol 67 (1993), pp. 1627-1637.
26. J. Arbiza, G. Taylor, J. A. Lopez, J. Furze, S. Wyld, and P. Whyte et al., Characterization of two antigenic sites recognized by neutralizing monoclonal antibodies directed against the fusion glycoprotein of human respiratory syncytial virus, J Gen Virol 73 (1992), pp. 2225-2234.

27. J. A. Lopez, R. Bustos, C. Orvell, M. Berios, J. Arbiza, and B. Barcia-Barreno et al., Antigenic structure of human respiratory syncytial virus fusion glycoprotein, J Virol 72 (1998), pp. 6922-6928.

28. J. A. Lopez, C. Penas, B. Garcia-Barreno, J. A. Melero, and A. Portela, Location of a highly conserved neutralizing epitope in the F glycoprotein of human respiratory syncytial virus, J Virol 64 (1990), pp. 927-930.

29. G. Zimmer, I. Trotz, and G. Hennler, N-glycans of F protein differentially affect fusion activity of human respiratory syncytial virus, J Virol 75 (2001), pp. 4744-4751. 